\title{
KNOWLEDGE AND PRACTICES ON THE SUBJECT OF ENERGY CONSERVATION AS PART OF PRIMARY SCHOOL $6^{\text {TH }}$ GRADERS' ENERGY LITERACY
}

\author{
Dimitrios Poimenidis ${ }^{1 *}$, Vasileios Papavasileiou ${ }^{2}$, Georgia loannidou ${ }^{3}$ \\ ${ }^{1} \mathrm{Dr}$, University of the Aegean, Greece, poimenidis@aegean.gr \\ ${ }^{2}$ Assoc. Prof. Dr., University of the Aegean, Greece, vpapavasileiou@rhodes.aegean.gr \\ ${ }^{3} \mathrm{PhD}$ Candidate, University of the Aegean, Greece, gina.ioannidou@gmail.com \\ ${ }^{*}$ Corresponding author
}

\begin{abstract}
Sustainable energy production and consumption is essential, directly linked to the environmental and social impacts and particularly related to the adults and students' energy literacy. It is a major educational issue as electricity is present in all human activities. Particularly, in the context of pedagogical approaches, the rational use, saving or non-use of energy and resources are linked to the knowledge, perceptions and habits of students, in order to design appropriate learning environments, as steps to develop environmentally friendly behaviors, through energy literacy. Thus, proper and effective education for children on energy issues establishes energy literacy in the context of environmental education and sustainability. The purpose of the study is to highlight the students' energy literacy, after attaining and completing basic education, before their transition to High School. The survey was conducted in May 2021 on 116 primary school students of the 6th grade in an urban area with an anonymous structured questionnaire, adapted to the children's language skills, while the data were analyzed with the SPSS 25 statistical program. The results indicate high levels of energy-related knowledge, as the statements show the adoption of basic practices of energy saving and use in daily life, in the context of environmental education and sustainability. They also demonstrate concisely a more complete and successful personal interconnection with the study issues through the educational process as a result of the successful educational approaches of basic education for the environment and sustainability, while some minor misunderstandings, mainly cognitive, do not seem to affect their positive energy efficiency behavior.
\end{abstract}

Keywords: sustainability, energy literacy, energy saving, knowledge, perceptions

\section{INTRODUCTION}

Energy is invisible yet it is all around us and affects our lifestyle, individually and socially (Coyle \& Simmons, 2014). Our daily life depends to a large extent on the abundance, the ease of finding and using energy, and the possibilities it offers us, while its imprint is considered indelible in our style of living (Oyedepo, 2012; Coyle \& Simmons, 2014). We are part of an ecosystem that is resilient in a sense and at the same time fragile with all the exerted pressures, natural and man-made, it receives. People's social life and economic activities reinforce this position directly through in flows of goods and services, and indirectly through 
ecosystem processes such as carbon sequestration, water purification, flood control, and recycling of nutrients (Everett et al., 2010). As the population increases worldwide, the Earth's resources deplete more rapidly since people require more of them (Martin et al., 2016). As a result, energy production and overconsumption have a negative impact on the environment and are the major cause (87\%) of greenhouse gas emissions (Roser, 2020). Therefore, decisions concerning energy production and use determine, among other things, carbon dioxide emissions intensity and climate change (Yeh et al., 2017). Consequently, overconsumption is based on two different issues. On the one hand, there are countries that have not developed energy technologies and therefore have low carbon dioxide emissions as their inhabitants do not have access to electricity and clean fuels for cooking but emit mainly carbon dioxide, as they use different types of fuel. On the other hand, there are countries that have developed energy technologies which release huge amounts of carbon dioxide into the atmosphere due to overconsumption (Ivanova \& Wood, 2020).

With the world population growth and industrialization on the rise in developing nations, humanity's hunger for energy has reached unprecedented levels. More than half of our energy comes from fossil fuels extracted from deep within the Earth's crust causing major environmental issues (Lay et al., 2013). The depletion of natural resources (Mittal \& Gupta, 2015), the increased carbon dioxide emissions, the alarming rise in global temperatures and the climate crisis are some of the interrelated issues of the energy consumption model (Ali et al., 2020). If greenhouse gas emissions are not reduced, significant long-term changes in the global climate could occur, with adverse effects on humans, industry, and the global economy. Therefore, the best answer to the current energy crisis would be a model not only of economic development but also of social dimension as a countermeasure to renewable energy sources, aimed at increasing energy efficiency, energy saving and rational use, and the adoption of clean energy production technologies (ICLEI, 2009).

In general, issues related not only to the production, use and energy distribution but also to a global energy crisis, must be addressed in an overall context that concerns energy producers and consumers, and the social environment shaped by its usage (Dark et al., 2014). Furthermore, as sustainable development is one of the main issues in education (Glavǐc, 2020; Papavasileiou, 2015; ICLEI, 2009), the direction of the social and economic development today should be low energy, low carbon emissions, and, mainly, the use of the most efficient forms of renewable energy sources (ICLEI, 2009). In addition to RES, the increasing energy efficiency, the decentralized energy system and the synergies among different sectors require the implementation of new methods and policies of energy planning (Dobravec et al., 2021). The provision of energy services in a sustainable way requires they be affordable to people, in ways that not only are currently sufficient but in the future as well so as to meet the basic needs and not be environmentally harmful (Oyedepo, 2012).

Regarding Greece at the local and national level, students need to understand how important it is to be familiar with the human activities and their impact on energy issues. Moreover, they need to comprehend the issue of fossil fuel depletion and the effects of the energy use on the ecosystem. This is extremely important as most of the energy sources used in the European Union are still non-renewable (Eurostat, 2021) and create a host of environmental problems and issues, despite the large increase in renewable energy sources.

Energy literacy is of great interest to those researching sustainable modes of use, particularly in the context of exploring its relationship with the energy issue and household energy consumption (van der Horst et al., 2016). Decisions on energy choices are determined not only by professionals and politicians, but also by every citizen who uses energy in daily life. Therefore, people must be adequately informed and energy literate (Lay et al., 2013). For this reason, education for environmental sustainability is of paramount importance and is a major contemporary educational challenge (Papavasileiou, 2015), as it allows students to acquire knowledge, become familiar with the rational management and implementation of energy saving practices in everyday life, turning them into critical thinkers (Poimenidis \& Papavasileiou, 2021). In addition, the study of students' certain characteristics contribute to the implementation of strategies that will change children's behavior in the long term (Lefkeli et al., 2018). Hence, experiential learning during childhood about the natural environment seems to be an essential factor in developing awareness of the physical environment and increasing individual responsibility and children's interest of environmental issues (Venter \& Ferreira, 2014).

\section{METHODOLOGY}

The current study explores the views, knowledge, and practices of primary school students, on the issue of energy management and the practical application in their personal lives, after completing the primary education cycle. Concurrently, it attempts to demonstrate the degree of success of the teaching approaches at the completion of the primary school curriculum which are related to energy and the basic practices 
implemented by the students, as the sixth graders have completed the subjects regarding their energy literacy.

The study was conducted in May 2021 with an anonymous questionnaire used as the most user-friendly and best responsive research tool to the objectives of this study (Fargas Malet et al., 2010, and which included 22 open-ended and closed-ended questions adapted to the children's language level. The questionnaire was given to 118 sixth graders of three primary schools in Rhodes with related socio-cultural characteristics. Sampling was random, while issues of ethics and research ethics were observed (Bryman, 2016; Cohen et al., 2017). The study incorporated questionnaires that were sufficiently completed by the children, while 2 were not included, as they presented many statistical gaps. The final sample in the study consists of 116 children ( 68 boys - 48 girls).

The response data were categorized, codified, and a database was created and processed with the SPSS 25 statistical program. The results of the study are presented with a descriptive percentage analysis and the statistically significant correlations $(p \leq .05)$ that were observed and need to be reported.

\section{STUDY FINDINGS}

Regarding the question which energy sources are considered renewable, $70.7 \%$ of the students correctly report wind power, solar energy, hydropower, biomass energy and geothermal energy, while there seems to be a misconception about the energy sources related to nuclear power $(10.3 \%)$ and power oil $(19 \%)$. In addition, $69 \%$ of them correctly state natural gas as a fossil fuel, while there are students who identify in correctly that biogas (12.1\%) and nuclear materials (19\%) are fossil fuels too. Moreover, $69 \%$ of the students correctly state oil as a non-renewable energy source, while many of them $(31 \%)$ report erroneously that oil is a renewable energy source. This is a matter for retraining as the level of its completion is extremely slow.

Concerning carbon dioxide emissions to air from some energy sources, $75.9 \%$ of the students report accurately that conventional energy sources (which contain carbon compounds) emit the greatest amounts of carbon dioxide $\left(\mathrm{CO}_{2}\right)$ into the atmosphere. There seems to be a misconception though, as $24.1 \%$ of them attribute carbon dioxide $\left(\mathrm{CO}_{2}\right)$ emissions to solar energy $(8.6 \%)$ and wind power $(15.5 \%)$, which is an issue that needs educational feedback.

According to the statements of most children (58.6\%),energy overconsumption together with energy efficiency are considered major factors that affect climate change, and this issue was approached educationally, whereas $41.4 \%$ of the children state that this issue was not undertaken educationally. Hence further remedial educational approaches need to be made.

When asked what the greenhouse effect is, $48.3 \%$ of the children state that it is "the heating of the Earth's atmosphere resulting solely from human activity", as they rightly focus on the anthropogenic dimension of the phenomenon's deterioration. $34.5 \%$ of them refer to it as "a natural process that regulates the temperature of the atmosphere" in the sense of science, while the rest of the children (17.2\%) associate the greenhouse effect exclusively with climate change.

Concerning the question "which atmospheric gas does not aggravate greenhouse effect?", $58.6 \%$ of the students answer correctly that it is oxygen, while the rest of the students $(41.4 \%)$ respond incorrectly that methane $\left(\mathrm{CH}_{4}\right)(27.6 \%)$ and carbon dioxide $\left(\mathrm{CO}_{2}\right)(13.8 \%)$ do not cause air pollution.

Regarding ways of reducing energy consumption in their households when room temperature is low and needs heating, the first thought of many children $(75.9 \%)$ is to wear an extra garment, unlike the statement of some children (24.1\%), that would simply increase the heating intensity in their households, increasing energy waste and carbon dioxide emissions.

When ventilating places that students visit or live in during the winter months, the central heating remains, mainly, off not only in the school unit (86.4\%) but also in the children's homes (86.4\%). Thus, energy use is reduced significantly resulting in resource efficiency and the depletion of carbon dioxide emissions.

In addition, the central heating in the school unit is set to $20^{\circ} \mathrm{C}$, an ideal temperature for sustainable energy as $55.2 \%$ of the students report, whereas several pupils $(31 \%)$ mention $18^{\circ} \mathrm{C}$ as minimum temperature. Very few children report $22^{\circ} \mathrm{C}$ as the highest temperature. Respectively the room temperature indicated in their household seems to be partially higher as $20^{\circ} \mathrm{C}$ is recorded to be the highest temperature by half of the students $(50 \%)$ while $25.9 \%$ of the children state $22^{\circ} \mathrm{C}$. $24.1 \%$ of the students report $18^{\circ} \mathrm{C}$ as the lowest room temperature.

The conversion of energy into electricity and its use, when derived from conventional sources, raises the biggest and most controversial issues of degradation and environmental burden in the ecosphere (E.I.A., 
2020). Hence, reducing electricity use is of great importance, particularly to children who shape their future energy profile through energy education (Poimenidis \& Papavasileiou, 2021).

Regarding energy saving practices at home, many students (69\%) state that they turn off the device they were using, such as TVs, computer screens and video game consoles, achieving energy efficiency through behavior change. Few students $(19.1 \%)$ report that they act in a fragmentary manner depending on the occasion, while even fewer children (12.1\%) admit that they do not switch off the devices. More specifically, $77.6 \%$ of the students deactivate their computers; $12.1 \%$ of the children leave their PC on standby whereas few students (10.3\%) are indifferent and leave their PC in full operation after use.

Many students $(55.2 \%)$ report that they turn off the light when leaving a room, reducing energy waste. However, $32.8 \%$ of them state that they act in a fragmentary manner whereas $12.1 \%$ do not switch the light off at all and this is a matter that needs reeducating children to be more environmentally responsible. The expected rates of implementing this practice were positively higher.

$74.1 \%$ of the pupils are unaware of the main sources of energy production in local and national level while few children mention oil (5.2\%) and the Sun (5.2\%) as energy sources that exist in Greece. In addition, this is a further issue of reeducating children.

The students report that energy saving light bulbs (72.4\%) are widely used in their school units while the rest $(27.6 \%)$ are referred as conventional incandescent light lamps. In the same question, it seems that the rates of energy saving globes' use are lower compared to the school units $(51.7 \%)$ whereas the standard incandescent lamps (48.3\%) are still used in the children's households. This is a matter that needs to be updated and adults be educated through programs in adult and informal education, or possibly through energy literacy workshops implemented in formal education which can involve the children's parents as part of parent-school collaboration.

Unplugging electrical appliances in the school unit when not in use to reduce waste energy, seems to be implemented quite satisfactorily, as $67.2 \%$ of the students report that this practice is executed, while $32.8 \%$ of them refer to this form of energy saving as not feasible. Regarding the children's' households, the percentages are lower as half of the families (50\%) unplug electrical appliances in their houses, while the other half $(50 \%)$ do not adopt this practice at all. This issue needs pedagogical approach either through nonformal education or through formal education with parent-school collaboration in training programs for energy saving and rational use in the household sector. Nevertheless, it is stated that parents buy mainly energyefficient devices, checking (72.4\%) the energy label on the device and choosing the one that is more energyefficient. $37.6 \%$ of children, though, report that energy labeling in not considered when purchasing electrical appliances.

From the intersections of the variables in terms of gender, it seems that girls are more knowledgeable of what are considered renewable energy sources (RES) than boys who have incomplete knowledge of the issue $\left(X^{2}=20.947 \mathrm{df}=2 \mathrm{p} .=0.001\right)$. Moreover, girls seem to know better that oil is a non-renewable energy source than boys $(X 2=7.898 \mathrm{df}=1 \mathrm{p} .=0.005)$. In addition, gender is significantly related to the girls' understanding on energy efficiency and climate change when there are class references on the issue $\left(X^{2}=\right.$ $5.035 \mathrm{df}=1 \mathrm{p} .=0.025)$. Girls further attribute the greenhouse effect to human activities that have been increasing the atmospheric concentration of greenhouse gases above the natural amount causing increased warming whereas boys consider that it is a natural phenomenon and process $\left(X^{2}=7.871 \mathrm{df}=2 \mathrm{p} .=0.020\right)$. Finally, girls state that they apply energy-saving practices in their homes more frequently as compared with boys $\left(X^{2}=14.417 \mathrm{df}=2 \mathrm{p} .=0.001\right)$.

The children's knowledge of what the greenhouse effect is, which is defined as an anthropogenic process of atmospheric heating in the study, is significantly associated with the statements about energy reduction practices. A further way of saving energy, which is added in the students' statements, is turning off the central heating during house ventilation $\left(X^{2}=14.417 \mathrm{df}=2 \mathrm{p} .=0.001\right)$. Moreover, the students would prefer to wear extra clothes, when the level of the heat output in the house is at a certain degree rather than increase the heating intensity, thus implementing significant energy savings $\left(X^{2}=10.836 \mathrm{df}=2 \mathrm{p} .=0.004\right)$. In addition, the students state that they turn off the lights when they leave a room in the house, thus saving electricity $\left(X^{2}=9.953 \mathrm{df}=4 \mathrm{p} .=0.041\right)$.

\section{DISCUSSION AND CONCLUSSIONS}

The issue of energy literacy, linked to the children's knowledge and daily practices is particularly important and in compliance with the objectives of education for environmental sustainability. Energy literate citizens make the right decisions on energy issues that determine the future of the ecosphere and the fate of future 
generations (Lay et al., 2012). Knowledge itself does not predetermine individual behavior but reinforces energy literacy which is inextricably linked to the students' environmentally friendly daily routines. Having a thorough understanding not only of the renewable energy sources, such as solar energy, wind power and water energy, but also of non-renewable sources, conforms with comprehending the negative effects of finite sources such as carbon on the environment. Climate change, which is recently referred to as climate crisis, linked with the greenhouse effect, are issues known to children and directly related to the overconsumption of natural resources that result in aggravating the phenomenon. Students seem to have achieved adept knowledge about the human intervention in the environment; they have increased awareness and have developed skills needed to identify and use energy resources (DeWaters \& Powers, 2013).

Regarding the students' daily practices about household heating, energy conservation is achieved by turning off the heating, setting the thermostat to the lowest comfortable temperature or preferring to wear extra garment instead of increasing the room temperature. These practices indicate that the students have adept knowledge of saving energy and are energy literate, resulting in adopting sustainable behavior and shaping the future by becoming active citizens who are environmentally concerned (Papaoikonomou, 2021; Poimenidis \& Papavasileiou, 2021).

Concerning electrical energy as the most used forms of energy in households, the students state that they the implement daily routines that result in efficiency, energy saving and rational use of energy. These practices include switching off the electrical appliances when not in use or disconnecting them from the main power source, deactivating the computer and turning off the lights, indicating that are environmentally aware and literate of behavioral adjustments to conserve energy.

Lastly, it seems that girls are more knowledgeable on energy sources and their distribution to renewable and non-renewable; they relate more accurately the greenhouse effect to human activities, and they adopt environmental behavior by implementing more energy saving practices in their homes compared to boys. This seems to lead to the need for more targeted education on related issues focusing on boys.

To conclude, as the statements indicate, school education has laid the foundation for reinforcing environmentally responsible behaviors and increasing energy literacy in later years when children become adults, who will make decisions and adopt sustainable behaviors to manage energy efficiently in their daily lives. The need for remedial teaching approaches towards the objectives of the study is very limited. Students' knowledge is aligned with the objectives of the education which aim to help people understand and evaluate the economic, social, and environmental impact of individual and collective decisions in the context of education for sustainable development (Merritt et al., 2019). Lastly, some student misconceptions of a purely cognitive or academic nature do not seem to affect significantly behaviors contributing to positive energy balance.

\section{REFERENCE LIST}

Ali, K. A., Ahmad, I. M. \& Yusup, Y. (2020). Issues, Impacts and Mitigations of Carbon Dioxide Emissions in the Building Sector. Sustainability, 12, 7427. doi: 10.3390/su12187427

Bryman, A. (2016). Social research methods. (5th ed.). London: Oxford University Press.

Cohen, L., Manion, L. \& Morrison, K. (2017). Research methods in education. Oxford, UK: Routledge Publishers.

Coyle, E. D. \& Simmons, R. A. (Eds.). (2014). Introduction. In Understanding the Global Energy Crisis, pp. 1-8. Purdue University Press. http://www.jstor.org/stable/j.ctt6wq56p.5

Dark, M., Ngambeki, I., Depew, D. \& Chong, R. (2014). Social Engagement by the Engineer. In E. D. Coyle \& R. A. Simmons (Eds.), Understanding the Global Energy Crisis, pp. 73-88. Purdue University Press. http://www.jstor.org/stable/j.ctt6wa56p.8

De Waters, J. \& Powers, S. (2013). Establishing Measurement Criteria for an Energy Literacy Questionnaire. The Journal of Environmental Education, 44(1), 38 - 55. https://naaee.org/eepro/research/library/establishing-measurement-criteria-energy

Dobravec, V., Matak. N., Sakulin, C. \& Krajačić, G. (2021). Multilevel governance energy planning and policy: a view on local energy initiatives. Energy, Sustainability and Society, 11(2), 
https://doi.org/10.1186/s13705-020-00277-y

E.I.A. (2020). Electricity explained. Electricity and the environment. Accessed 27.10.2021 from: https://www.eia.gov/energyexplained/electricity/electricity-and-the-environment.php

Eurostat. (2021). Energy statistics - an overview. Accessed 19-10-2021 from: https://ec.europa.eu/eurostat/statistics-explained/index.php?title=Energy statistics - an overview

Everett, T., Ishwaran, M., Ansaloni, G.P. \& Rubin, A. (2010). Economic Growth and the Environment. Defra Evidence and Analysis Series, Paper 2, Defra.

Fargas Malet, M., McSherry, D., Larkin, E. \& Robinson, C. (2010). Research with children: methodological issues and innovative techniques. Journal of Early Childhood Research, 8(2), 175-192. https://doi.org/10.1177/1476718X09345412

Glavic, P. (2020). Identifying Key Issues of Education for Sustainable Development. Sustainability, 12, 6500. doi:10.3390/su12166500

ICLEI. (2009). Sustainable Urban Energy Planning. A handbook for cities and towns in developing countries. United Nations Human Settlements Programme, UN HABITAT, UNEP.

Ivanova, D. \& Wood, R. (2020). The unequal distribution of household carbon footprints in Europe and its link to sustainability. Global Sustainability, 3 (18), 1-12. https://doi.org/10.1017/sus.2020.12

Lay, Y-F., Khoo, C-H., Treagust, D. F. \& Chandrasegaran, A. L. (2013). Assessing secondary school students' understanding of the relevance of energy in their daily lives. International Journal of Environmental \& Science Education, 8 (1), 199-215.

Lefkeli, S., Manolas, E., loannou, K. \& Tsantopoulos, G. (2018). Socio-Cultural Impact of Energy Saving: Studying the Behaviour of Elementary School Students in Greece. Sustainability, 10, 737. doi:10.3390/su10030737

Martin, J-L., Maris, V. \& Simberloff, S. D. (2016). The need to respect nature and its limits challenges society and conservation science. PNAS, 113 (22), 6105-6112.

Merritt, G. E., Bowers, N., Rimm-Kaufman, E. S. (2019). Making connections: Elementary students' ideas about electricity and energy resources, Renewable Energy, 138,1078-1086, ISSN 09601481,https://doi.org/10.1016/j.renene.2019.02.047

Mittal, I. \& Gupta, R. K. (2015). Natural Resources Depletion and Economic Growth in Present Era. SOCH Mastnath Journal of Science \& Technology (BMU, Rohtak), 10 (3), ISSN: 0976-7312. Available at SSRN: https://ssrn.com/abstract=2920080

Oyedepo, S. O. (2012). Energy and sustainable development in Nigeria: the way forward. Energy, Sustainability and Society, 2 (15). https://doi.org/10.1186/2192-0567-2-15

Papaoikonomou, D. A. (2021). An ordinal logistic regression model on civic education usefulness in Greece: empirical research in a sample of university students. Journal of Research in Humanities and Social Science, 9(2), 18-25 ISSN (Online): 2321-9467.

Papavasileiou, V. (2015). Sustainable Development and Education: A multidimensional relationship. Athens: Diadrasi. (in Greek)

Poimenidis, D \& Papavasileiou, V. (2021). Energy literacy, recycling and rational use of materials in the daily life in students of the fifth class primary schools of an urban area. International E-Journal of Advances in Social Sciences, Vol. VII, Issue 20, 405-413.

Poimenidis, D \& Papavasileiou, V. (2021). Investigation of energy literacy, practices of saving and rational use of electricity in students of fifth grade of primary schools. International E-Journal of Advances in Education, Vol. VII, Issue 20, 81-89.

Poimenidis, D \& Papavasileiou, V. (2021). Primary school students' cognitive awareness on bicycling as energy literacy in the context of education for sustainability. Journal of Language and Education Policy, 2(4) 14-21. DOI: 10.48150/jlep.v2no4.2020.a3. ISSN:2691-6061

Roser, M. (2020). The world's energy problem. Accessed 18/10/2021 from https://ourworldindata.org/worldsenergy-problem

van der Horst, D., Harrison, C., Staddon, S. \& Wood, G. (2016). Improving energy literacy through student- 
led fieldwork - at home. Journal of Geography in Higher Education, 40(1), 67-76. doi: 10.1080/03098265.2015.1089477

Venter, E. \& Ferreira, G. J. (2014). A Plea for Environmental Education That Focuses on Learning to Care. Journal of Human Ecology, 46(1), 33-38. doi: 10.1080/09709274.2014.11906703

Yeh, S-C., Huang, J-Y. \& Yu, H-C. (2017). Analysis of Energy Literacy and Misconceptions of Junior High Students in Taiwan. Sustainability, 9, 423. doi: 10.3390/su9030423 